\title{
RSSI Based Localization of Bluetooth Devices for Visually Impaired
}

\author{
Muhammad Irfan Aziz¹, Thomas Owens², Uzair Khaleeq-uz-Zaman³, Muhammad Bashir Akbar1 \\ ${ }^{1}$ National University of Sciences and Technology, Islamabad, Pakistan \\ ${ }^{2}$ Department of Electronic and Computer Engineering Brunel University, West London, UK \\ ${ }^{3}$ Laboratoire de Conception Fabrication Commande, Ecole Nationale Supérieure d'Arts et Métiers, Metz, France \\ Email: iirfanaziz@gmail.com, dia ry58pk@gmail.com, thomas.owen s@brunel.ac.uk, uzair-khaleeq-u z.zaman@ensam.eu
}

How to cite this paper: Aziz, M.I., Owens, T., Khaleeq-uz-Zaman, U. and Akbar, M.B. (2019) RSSI Based Localization of Bluetooth Devices for Visually Impaired. Journal of Signal and Information Processing, 10, 37-57.

https://doi.org/10.4236/jsip.2019.102004

Received: March 20, 2019

Accepted: May 3, 2019

Published: May 6, 2019

Copyright $\odot 2019$ by author(s) and Scientific Research Publishing Inc. This work is licensed under the Creative Commons Attribution International License (CC BY 4.0).

http://creativecommons.org/licenses/by/4.0/

\begin{abstract}
Localization for visually impaired people in dynamically changing environments with unexpected hazards and obstacles is a current need. Many techniques have been discussed in the literature with respect to location-based services and techniques used for the positioning of devices. Time difference of arrival (TDOA), time of arrival (TOA) and received signal strength (RSS) have been widely used for the positioning but narrow band signals such as Bluetooth cannot efficiently utilize TDOA or TOA. Received signal strength indicator (RSSI) to measure RSS, has been found to be more reliable. RSSI measurement estimations depend heavily on the environmental interference. RSSI measurement estimations of Bluetooth systems can be improved either by improving the existing methodologies used to implement them or by using fusion techniques that employ Kalman filters to combine more than one RSSI method to improve the results significantly. This paper focuses on improving the existing methodology of measuring RSSI by proposing a new method using trilateration for localization of Bluetooth devices for visually impaired people. To validate the new method, class 2 Bluetooth devices (Blue Giga WT-12) were used with an evaluation board. The software required was developed in National Instruments LabView. The PCB was designed and manufactured as well. Experiments were then conducted, and surface plots of Bluetooth modules were obtained to show the signal interference and other environmental effects. Lastly, the results were discussed, and relevant conclusions were drawn.
\end{abstract}

\section{Keywords}

Bluetooth, Localization, Navigation Assistance, Received Signal Strength Indicator, Visually Impaired 


\section{Introduction}

The navigation from one place to another addressing the security and mobility of visually impaired persons travelling through city streets and buildings in unfamiliar environments is a major political and technical challenge for modern society [1] [2]. According to the World Health Organization (WHO), estimated 253 million people live with vision impairment of which 36 million are blind and 217 million have moderate to severe vision impairment [3]. The knowledge typically required for navigation by the blind is a mixture of declarative and route knowledge [4]. Most of the time visually impaired persons must rely on regular and repetitive routes with the least obstructions. They often participate in orientation and mobility $(\mathrm{O} \& \mathrm{M})$ sessions where instructors provide training to get familiar with a new space. However, due to dynamically changing environments with unexpected hazards and obstacles, localization and location-based services (LBS) which are adaptable, time saving, cost- and user-friendly, are needed [5] [6]. The Global positioning system (GPS) has been used over the years with unparalleled success for outdoor environments [7] [8] but for localization indoors, or near high rise structures, GPS deteriorates considerably due to technical constraints such as shadowing and multi-path disturbances. Moreover, GPS must rely on relative positioning incorporating sensors like digital tags, active badges, thermistors, accelerometers, photodiodes and beacons [9]. Therefore, alternatives such as ultrasound [10], radio frequency identification transponders [11], using a robotic dog-guide [12], or an instrumented white cane [13], have been used for mobility and indoor orientation tasks for visually impaired people. For indoor human position sensing, real-time location systems (RTLS) based on distributed wireless sensor networks have also been in use. For instance, ultra-wide-band (UWB), wireless LAN (WLAN), and radio frequency identification (RFID) have been combined with a building information model (BIM) to propose an emergency navigation system for use in complex buildings [14]. Furthermore, radio map approaches using Bluetooth and Wi-Fi have also assisted in providing an indoor positioning system (IPS) [15].

Localization, vital for LBS, can be achieved in several ways. Time of arrival (TOA), time difference of arrival (TDOA) and received signal strength (RSS) are the popular methods but narrow band signals such as Bluetooth and Zigbee cannot efficiently utilize TDOA or TOA and using received signal strength indicator (RSSI) to measure RSS is much more reliable in which measurement estimations depend heavily on the environmental interference and are also nonlinear [16] [17]. Moreover, triangulation, trilateration and multilateration are well-studied and well applicable positioning methods. Triangulation finds the position of the desired point using angles, trilateration finds the same result using distances, whereas, multilateration employs TDOA. Moreover, the location of a node in a sensor network is very important and advances in technology have made it possible to employ low cost multiple nodes, thus enabling them to measure distance using RSSI effectively, which is a direct gauge of distance [18]. 
Signals from Access Points (APs) can be read and calculated by RSSI methods and the system is implemented in devices capable of Bluetooth technology using trilateration methods.

Bluetooth wireless is a short-range communications technology originally intended to replace the cables connecting portable and/or fixed devices while maintaining high levels of security. Bluetooth-based localization is a not a novel idea but due to the limitations of the original Bluetooth specification this approach has not been widely used [19]. Bluetooth transmitters, when invoked by the users, transmit pre-recorded voice messages if installed at regular intervals. Hence, they provide information about users' current position and nearby points of interests [20]. Devices capable of the Bluetooth function can connect several other devices to Personal Area Networks (PANs) and positioning error can be reduced by constructing an accurate and proper position algorithm, and by improving the RSSI reading accuracy [21]. Further, compared to Ethernet based WiFi networks, the available services of Bluetooth and their discovery are relatively simple, allowing the communication to go more smoothly.

The Bluetooth, in general, has been primarily used for data transfer. This paper proposes a new methodology using trilateration for localization of Bluetooth devices using RSSI for visually impaired people. To validate the proposed method class 2 Bluetooth devices (Blue Giga WT-12) were used along with an evaluation board. The required software was developed in National Instruments LabView. The Printed Circuit Board (PCB) used for validation was designed and manufactured. Experiments were then conducted, and surface plots of Bluetooth modules were obtained to show the signal interferences and other environmental effects. The rest of the paper is divided as follows: Section 2 presents a literature review of localization methods with a special focus on RSSI based localization of Bluetooth devices for visually impaired people; Section 3 presents the proposed methodology; Section 4 describes the conducted practical experiments; and finally, Section 5 discusses the results of the experiments and the conclusions drawn.

\section{Literature Review}

For visually impaired people, being able to connect with social activities is a difficult task, especially when it requires navigation in an outdoor environment. By focusing on residual senses, visually impaired people can sense and learn the surrounding environment through multi-sensory channels and $\mathrm{O} \& \mathrm{M}$ sessions. These guidelines help them identify specific landmarks (navigation cues) which are then used in the construction of a mental map [22] But due to dynamically changing environments, the commute of the visually impaired can no longer just rely on these so-called "mental maps".

GPS is undoubtedly the most powerful and widely used navigation tool for outdoor environments, but its performance drops considerably in indoor conditions and around high-rise buildings. Assistive technologies have been used in 
the past that use both GPS and geographic information system (GIS) in smartphones such as VoiceOver, a screen reader built into the system that enables the visually impaired to access information via spoken descriptions, TapTapSee which enables the camera to identify objects and speak out loud to the user, and BlindSquare which provides information about the surrounding environment in terms of points of interest with an audible feedback. As GPS has limited indoor applications because of its limitations, researchers have studied a lot of Indoor Positioning Systems (IPSs).

The RFIDs have been extensively used for indoor navigation purposes. Park and Hashimoto [23] used an electric wheel chair as a robot and passive RFIDs installed in a grid. A passive RFID information grid was also proposed by Willis and Helal [24] to aid the blind on a college campus. RFID tags were further employed by Maneesilp et al. [25] to implement a 3D localization system. To maintain orientation of blind persons during walking, Amemiya et al. [26] used active RFID tags to simulate virtual leading blocks analogous to conventional leading blocks, which are pavement blocks with a serrated surface. A combination of RFID tags, RFID cane reader and personal digital assistant (PDA) was also used by D'Atri et al. [27] to define orientation of visually impaired people with respect to both origin and destination.

Moreover, since the direction of arrival (DOA) is imperative in multiple signal sources, there are various methods discussed in literature to find it. Multiple signal classification (MUSIC) algorithm has been used quite popularly to minimize the effects of ground reflections by calibrating commercial electromagnetic compatibility (EMC) antennas [28] and understanding the physical presence of noise and other adverse effects [29]. Estimation method of Signal Parameters via Rotational Invariance Technique (ESPRIT) was used by Beamspace et al. [30] to utilize a self-initiating MUSIC based direction finder (DF) in an Acoustic Particle Velocity-Field as a coarse DF and starting point for MUSIC. DOA can also be found using an Adcock DF ADF [31]. Using Infra-Red (IR), Radio Frequencies (RF) and ultrasound, Paul and Van [32] evaluated several systems including, Active Badge, Cricket, Sonitor, RADAR, Place-Lab, Horus WLAN location determination system, Ekahau, and Ubisense. To perform pedestrian localization, Wireless sensor networks were also used by Ahn and Ko [33].

Having discussed the methods to find the DOA, it is important to shed light on the different methods used to find the distance between a transmitter and a receiver. TDOA, TOA and RSS measurements have been used quite extensively in the literature but as narrow band signals like Bluetooth cannot utilize TDOA and TOA efficiently, RSS has been the popular choice [16]. As RSSI is a complex function that depends upon distance and is easily interfered with by noisy wireless channels, systems that utilize RSSI usually construct an RF fingerprint of the region which they're interested in, an example is "Cellsense" which was developed by Ibrahim and Youssef [34] using a combination of deterministic and probabilistic techniques. It follows that "trilateration" and "fingerprinting" are two basic techniques used in many IPSs. Chen et al. [35] [36] combined pede- 
strian dead reckoning (PDR) with a weighted path loss (WPL) algorithm that was based on the log-distance path loss model between a router and a client, under an extended Kalman filter. Danis and Cemgil [37] constructed a model tailored specifically for RSSI fingerprints. RSSI schemes are further being used widely almost everywhere in WLAN to give location aware services [38]. In addition, finding the maximum value for RSSI is important in localization and was found by Sahu et al. [39] by calculating a polynomial for all the RSSI and then selecting the highest value. It was found that fluctuations in RSSI values increased as the terrain changed from plain to uneven and therefore, calculating the point of intersection of the perpendiculars that pass through the maximum RSSI point, determined the sensor position. Frequency Modulation (FM) and WiFi vectors for RSSI were combined to check the effect on localization accuracy by Chen et al. [40].

Bluetooth refers to an open specification for a technology which enables short-range wireless voice and data communications. The most common forms of telecommunications across the world operate over licensed bandwidths producing revenues for governments. A core idea behind Bluetooth was to make it free of the restrictions associated with licensed bandwidths. So, it was designed to operate over the Industrial, Scientific and Medical (ISM) band of $2.4 \mathrm{GHz}$ which is free to use in most of the world [41]. At only room level, a low-cost Bluetooth-based positioning system was developed by Cheung et al. [42]. The system required a beacon which had to be initialized and wrapped thereby requiring lot of on-site time and was not being able to recover in cases of power outages. Such systems can only be applicable in scenarios where a few beacons or tolerance of longer positioning determination times are required. Further, Bluepass was developed by Diaz et al. [43] to be suitable for different indoor environments. Hossain and Soh [44] evaluated different characteristics of Bluetooth like RSSI, link quality (LQ), transmit power level, etc., and concluded that a combination of LQ and RSSI is a viable option for localization purposes. To conclude that only positive values of RSSI can be used for a functional approximation of the distance between a receiver and a transmitter, Feldmann et al. [45] utilized the golden receiver power rank (GRPR) which is a specific range of RSSI between the optimal receiver range and RSS. Since, to secure accurate location services without triangulation from more than three Bluetooth base stations is very difficult, Altini et al. [46] described a region-based localization method that adopts a probabilistic approach based on a multitude of queries as well as feedback. Using triangulation, Li and Wang [47] calculated the current location as the unique point of intersection of all the three circles corresponding to three Bluetooth transmitters. With specific focus on the visually impaired, Bohonos et al. [48] demonstrated the utility of Bluetooth as an aid for the blind when crossing a road intersection using an implementation on a mock setup. The possibility of using fluorescent light communication (FLC) coupled with Bluetooth and RFID tags installed at different locations, was tested by Liu et al. [49] which 
greatly improved the overall reliability and accuracy of the system.

Based on the literature reviewed and the over-arching aim of this research, it has been found that the methods proposed in the literature with respect to determining the RSSI of Bluetooth systems can be further improved either by improving the existing methodologies to implement them or using fusion techniques by employing Kalman filters to combine more than one method in order to improve the results significantly. This paper focuses on the techniques for improving the existing methodology for measuring RSSI and then finding the source to help localization of the subject from the Bluetooth devices.

\section{Proposed Methodology}

\subsection{Trilateration Using RSSI}

Trilateration works by measuring the distances between two points and then solving for the desired results using geometry of circles, spheres and/or triangles [49]. Since, RSSI is very difficult to measure accurately due to many reasons such as multipath fading, reflections, environmental noises, and conditions. There is no standard formula for using RSSI to measure distance in all the scenarios. In most cases, a calibration is done with known parameters, and then based on the data, a formula is used to calculate unknown location.

In this paper, a different approach was adopted from that available in literature for trilateration. Instead of finding the circles of power, the normal to line connecting the circles was determined as explained below. If we assume that the object of interest is transmitting an RF signal which can be heard by at least three different receivers, then depending upon the power received by each of them, trilateration can be done (see Figure 1).

Figure 1(a) shows three unique receivers: $P_{1}, P_{2}$ and $P_{3}$, marked by their area of listening as yellow, green and blue, respectively. The object of interest $(A)$ for which triangulation is intended and is at point $(x, y)$. Since the coordinates of $P_{1}$, $P_{2}$ and $P_{3}$ are fixed and known, the distances between them (such as $D_{1}, D_{2}$ and $\left.D_{3}\right)$ are also known. $P_{1}, P_{2}$ and $P_{3}$ make a triangle and three perpendiculars are drawn from each side of the triangle to the location of $(x, y)$. These perpendiculars are $\overline{L_{1}}, \overline{L_{2}}$ and $\overline{L_{3}}$ respectively, and each divide lines $\overline{D_{1}}, \overline{D_{2}}$ and $\overline{D_{3}}$ in such a way that $D_{1}$ is broken into two segments $R_{x 12}$ and $R_{x 21}$ with $D_{1}=R_{x 12}+R_{x 21}, D_{2}$ is broken into $R_{x 23}$ and $R_{x 32}$ with $D_{2}=R_{x 23}+R_{x 32}$; and $D_{3}$ into $R_{x 13}$ and $R_{x 31}$ with $D_{3}=R_{x 13}+R_{x 31}$, respectively. If equations of lines $\overline{L_{1}}, \overline{L_{2}}$ and $\overline{L_{3}}$ are found, the error-region or probable location of point $(x, y)$ can be found as illustrated in Figure 1(b).

Since RSSI given by $P$ is a direct gauge of the distance $R$, i.e., $P \propto \frac{1}{R^{2}}$, the relationship between receivers $P_{1}$ and $P_{2}$ can be depicted by Equation (1):

$$
\frac{P_{R S S I @ 1}}{P_{R S S I @ 2}}=\left(\frac{R_{x 21}}{R_{x 12}}\right)^{2}
$$




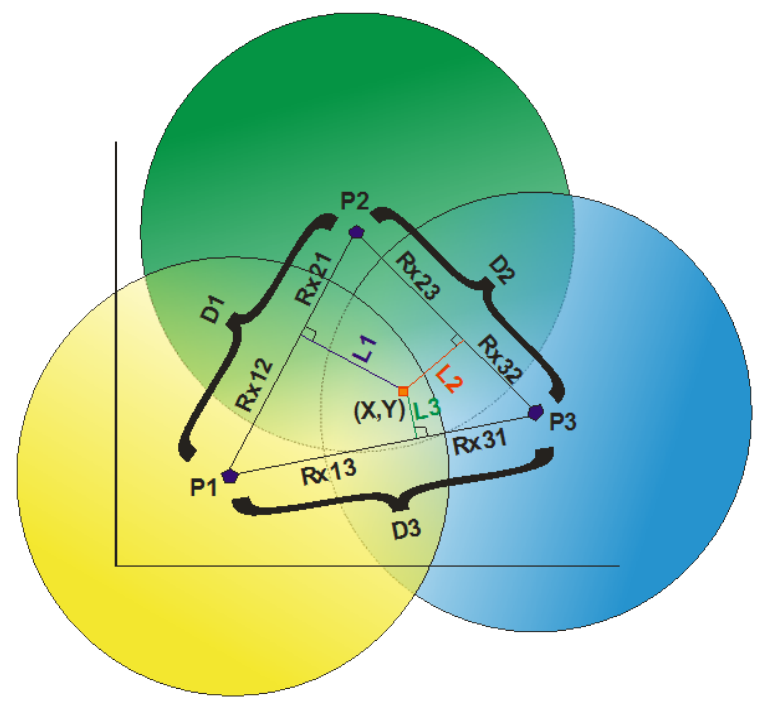

(a)

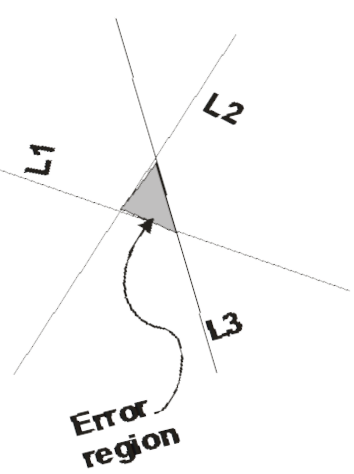

(b)

Figure 1. (a) Overlapping areas of three receivers depending upon Theoretical RSSI. (b) Error region depicting position of actual target.

where $P_{\text {RSSI } @ 1}$ and $P_{\text {RSSI @2 }}$ are the received powers at $P_{1}$ and $P_{2}$, respectively while $R_{x 21}$ and $R_{x 12}$ are the distances aggregated to show the distance between receivers $P_{1}$ and $P_{2}$. (1) can be re-written as shown in Equation (2),

$$
R_{x 12}=\frac{D_{1}}{1+\sqrt{\left(\frac{P_{R S S I @ 1}}{P_{R S S I @ 2}}\right)}}
$$

Similarly, $R_{x 23}$ and $R_{x 31}$ can be obtained as shown in Equations (3) and (4):

$$
\begin{aligned}
& R_{x 23}=\frac{D_{2}}{1+\sqrt{\left(\frac{P_{R S S I @ 2}}{P_{\text {RSSI@3 }}}\right)}} \\
& R_{x 31}=\frac{D_{3}}{1+\sqrt{\left(\frac{P_{R S S I @ 3}}{P_{R S S I @ 1}}\right)}}
\end{aligned}
$$

Once $R_{x 12}$ is known, $R_{x 21}$ can be found in a similar way as can $R_{x 32}$ and $R_{x 13}$. The crossing points of $\overline{L_{1}}\left(x_{D 1}, y_{D 1}\right)$ on $\overline{D_{1}}, \overline{L_{2}}\left(x_{D 2}, y_{D 2}\right)$ on $\overline{D_{2}}$ and $\overline{L_{3}}\left(x_{D 3}, y_{D 3}\right)$ on $\overline{D_{3}}$ are given by Equations (5), (6), and (7), respectively:

$$
\left\{\begin{array}{l}
x_{D 1}=x_{1}+\left(x_{2}-x_{1}\right)\left(\frac{R_{x 12}}{D_{1}}\right) \\
y_{D 1}=y_{1}+\left(y_{2}-y_{1}\right)\left(\frac{R_{x 12}}{D_{1}}\right)
\end{array}\right.
$$




$$
\begin{aligned}
& \left\{\begin{array}{l}
x_{D 2}=x_{2}+\left(x_{3}-x_{2}\right)\left(\frac{R_{x 23}}{D_{2}}\right) \\
y_{D 2}=y_{2}+\left(y_{3}-y_{2}\right)\left(\frac{R_{x 23}}{D_{2}}\right)
\end{array}\right. \\
& \left\{\begin{array}{l}
x_{D 3}=x_{3}+\left(x_{1}-x_{3}\right)\left(\frac{R_{x 31}}{D_{3}}\right) \\
y_{D 3}=y_{3}+\left(y_{1}-y_{3}\right)\left(\frac{R_{x 31}}{D_{3}}\right)
\end{array}\right.
\end{aligned}
$$

Using basics from trigonometry, the final equations of $\overline{L_{1}}, \overline{L_{2}}$ and $\overline{L_{3}}$ can be known as shown in Equations (8), (9), and (10) respectively:

$$
\begin{aligned}
& y_{L 1}=\left(\frac{x_{1}-x_{2}}{y_{2}-y_{1}}\right) x_{L 1}+\left(\frac{R_{x 12}}{D_{1}}\right)\left(\left(y_{2}-y_{1}\right)+\left(\frac{\left(x_{1}-x_{2}\right)^{2}}{y_{2}-y_{1}}\right)\right), \\
& y_{L 2}=\left(\frac{x_{2}-x_{3}}{y_{3}-y_{2}}\right) x_{L 2}+\left(\frac{R_{x 23}}{D_{2}}\right)\left(\left(y_{3}-y_{2}\right)+\left(\frac{\left(x_{2}-x_{3}\right)^{2}}{y_{3}-y_{2}}\right)\right), \\
& y_{L 1}=\left(\frac{x_{1}-x_{2}}{y_{2}-y_{1}}\right) x_{L 1}+\left(\frac{R_{x 12}}{D_{1}}\right)\left(\left(y_{2}-y_{1}\right)+\left(\frac{\left(x_{1}-x_{2}\right)^{2}}{y_{2}-y_{1}}\right)\right),
\end{aligned}
$$

The solution of these lines (their intersection with each other) will result in the error triangle. The area inside the triangle is the probable location of the transmitter.

\subsection{Bluetooth Module}

The Bluetooth Module used was one of the Blue Giga WT-12 modules as shown in Figure 2. The module is a class 2 Bluetooth device with a range of 10 meters. This module had its own built-in chip antenna.

The WT-12 Bluetooth module also comes with an evaluation board, having all the basic communication interfaces already installed and working. The evaluation board as shown in Figure 3 was used as an inquiry generator for all the five Bluetooth receivers.

\subsection{Graphical User Interface (GUI) for Calculating RSSI}

The Evaluation Board shown in Figure 3 was hooked up with a Laptop and software was developed in National Instruments LabView, the GUI of which is shown in Figure 4. The evaluation kit along with the laptop was designated as "Inquirer" and through it, the registers of the Bluetooth could be accessed for getting the value of RSSI. The RSSI value measured is not as close to the exact value as one would get through a standard spectrum analyzer or power meter, rather, it is an indication of how much power was received as compared to a Golden Ratio-which itself is manufacturer specific. Hence, if the RSS is more than the Golden Power Ratio, then the RSSI returned would be that much $\mathrm{dBm}$ 


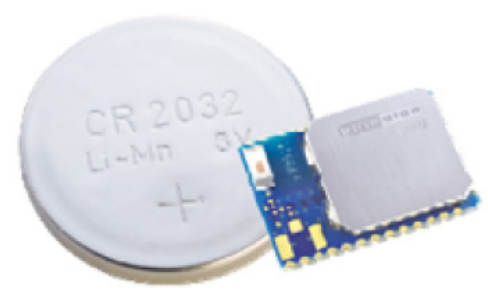

Figure 2. The Blue Giga WT-12 Bluetooth module.

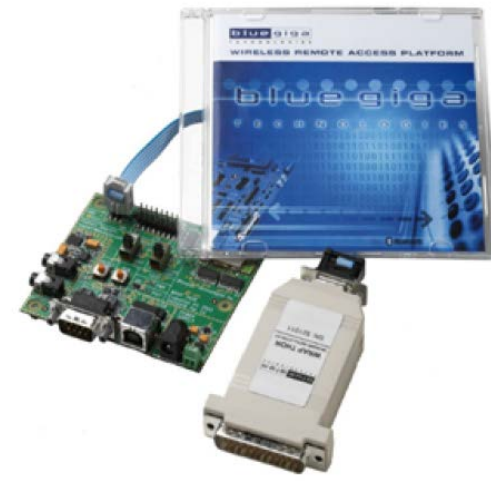

Figure 3. WT-12 evaluation board.

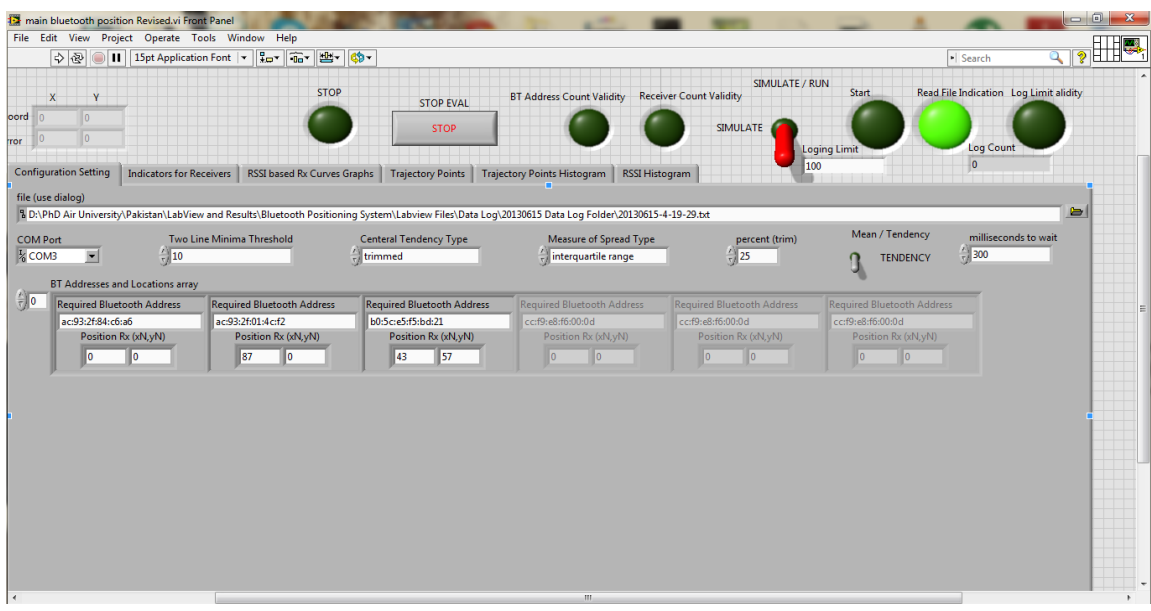

Figure 4. The GUI for calculating RSSI through inquiries.

positive and would be shown as $+\mathrm{dBm}$, but on the other hand if the RSS is less than the Golden Power Ratio, then the RSSI returned by the register would be negative and would thus be shown as $-\mathrm{dBm}$. The GUI was designed in such a way that it could record all the values from the register of the Bluetooth Module after the Inquiry cycle. In addition to this, MAC addresses of all the Bluetooth modules along with their location on the experimental space of $15 \times 15 \mathrm{ft}$ grid could also be entered before the start of the tests. The inquiry cycle was run 25 times at each spot, whose coordinates were manually changed after each run. The data was then stored in a ".csv" format and re-arranged to improve its readability. 


\subsection{Design and Manufacture of PCB for Bluetooth Module}

The PCB was indigenously designed and manufactured. The schematic diagrams of the PCB are shown in Figure 5. OrCad software was used to design and develop the two layered PCB and importance was given to the antenna portion of the Bluetooth module, as it was supposed to be copper free on both sides along with grounding holes on both top and bottom layers with copper pour. All the footprints of the components were also made from scratch. The footprint for Bluetooth module was quite challenging due to probability of RF interference being generated if the footprint was not proper. Interconnection among the RS-232 ports, Power supply and WT-12 module was kept at minimum to reduce the effect of radiation on long wires. The design of the PCB was quite a challenging task since it required that the PCB should not only be error free, but also noise free, as mixed signal noise could hamper the performance of the Bluetooth module severely. Moreover, the PCB was a double-sided board and its layers are shown in Figure 6.

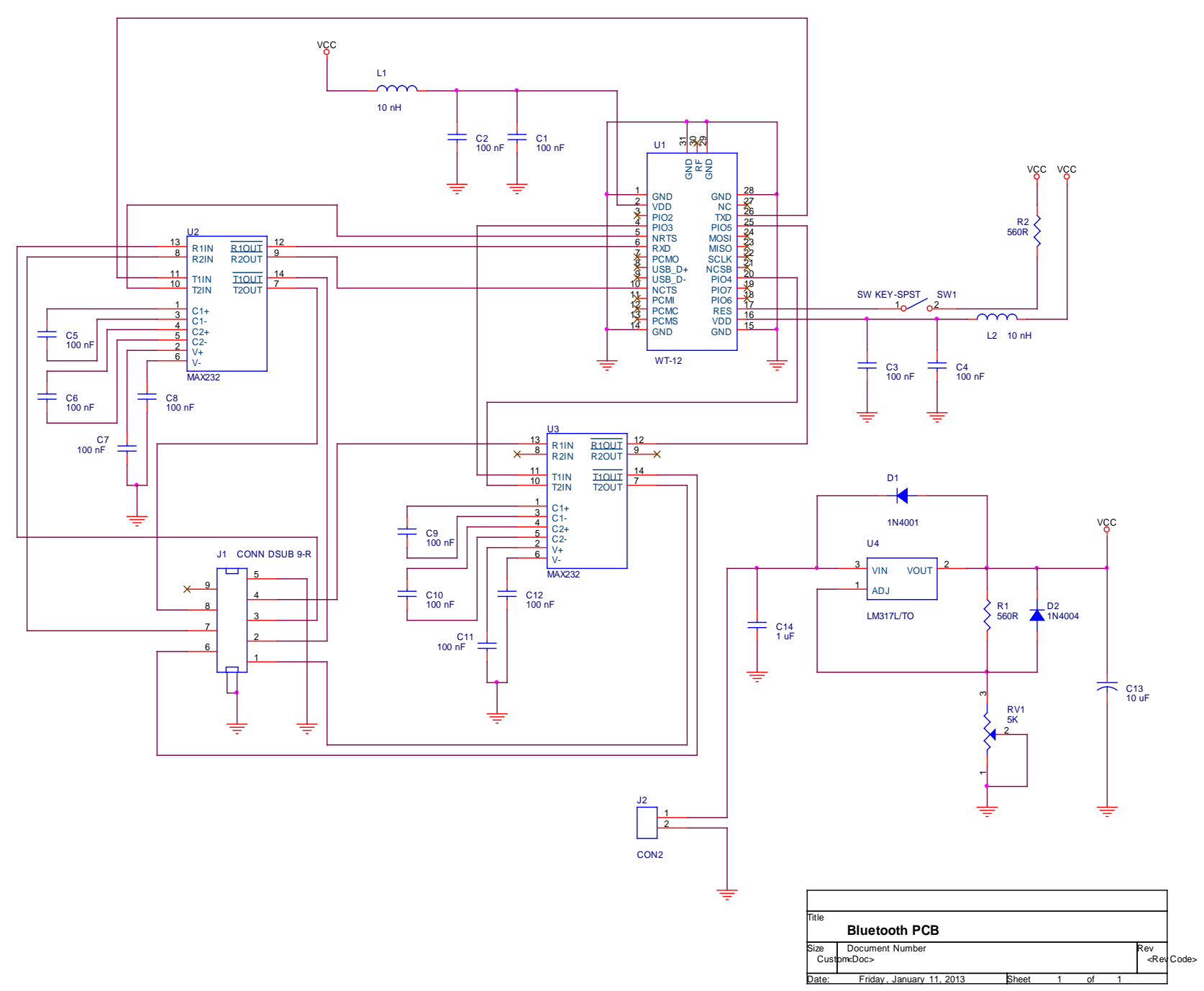

Figure 5. Schematic diagram of indigenously designed WT-12 Bluetooth module. 

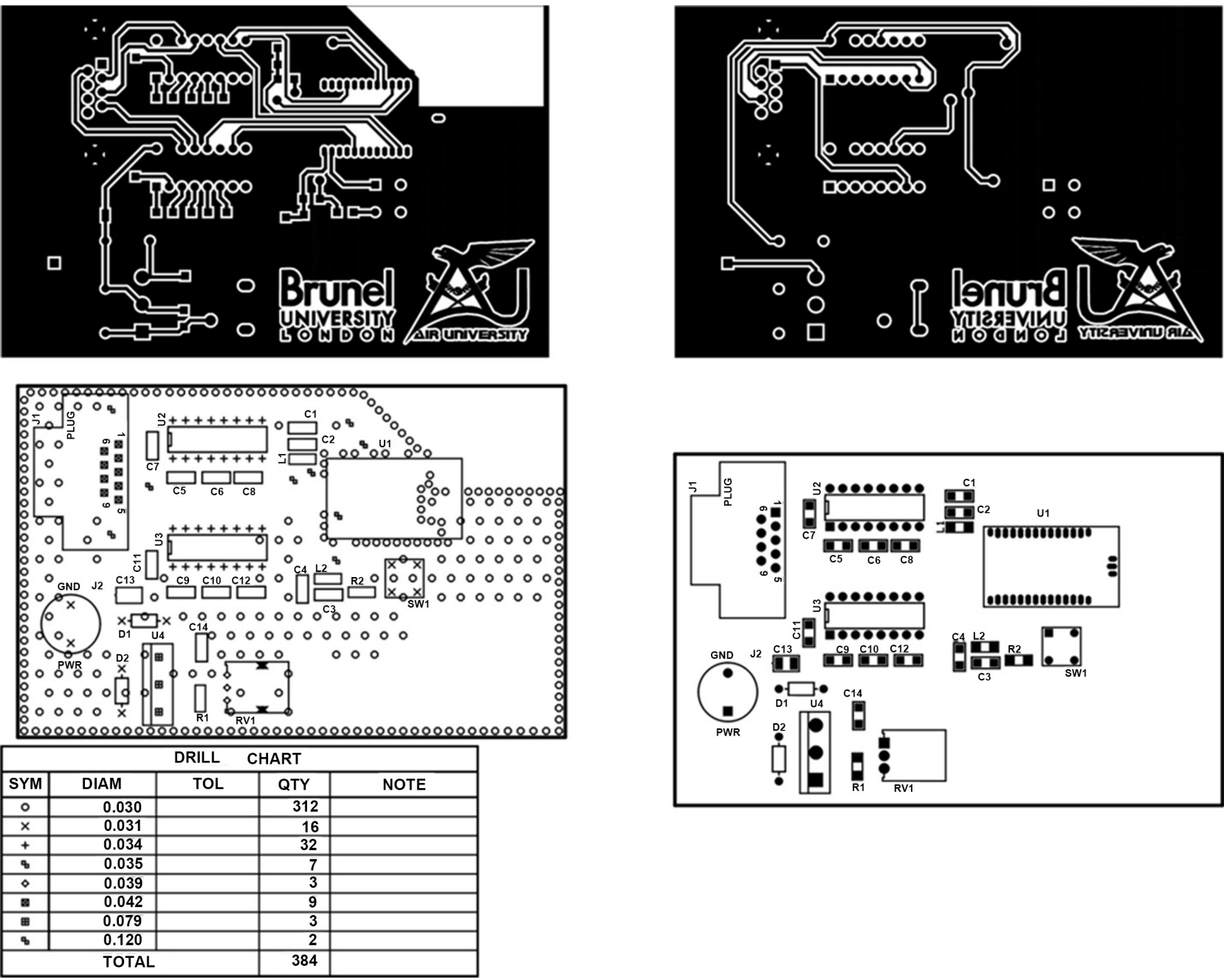

Figure 6. Various PCB layers and its layout.

\section{Experiments}

In this experiment five Bluetooth modules were placed on a grid of $15 \times 15 \mathrm{ft}$ as shown in Figure 7 , at coordinates of $(0,0),(15,0),(7.5,7.5),(0,15)$ and $(15,15)$. These modules were pre-calibrated, so that their response curve was already known. The inquiry module (WT-12 Evaluation Board connected to the Laptop) was placed at each grid point, starting from $(2,0) \mathrm{ft},(4,0) \mathrm{ft}$ and so on till $(14,0) \mathrm{ft}$ and then it was moved to $(0,2) \mathrm{ft},(2,2) \mathrm{ft}$ and so on up to $(15,2)$ and this process continued until all the 77 -grid points were covered except $(0,0) \mathrm{ft},(15,0) \mathrm{ft},(0,15)$ $\mathrm{ft}$ and $(15,15) \mathrm{ft}$ since they were occupied by the four receiver modules with the fifth one at $(7.5,7.5) \mathrm{ft}$. At each point 25 inquiry recordings were made for each receiver. At each grid-point, 25 inquiries were initiated to each receiver and signal strength (RSSI) was recorded for the replied signal.

Before starting the experiment, calibration of each module was carried out separately. The data of the calibration was recorded with 1000 readings at each point from 2 feet to 22 feet at intervals of 2 feet, i.e., for each receiver, RSSI was measured with the help of Spectrum Analyzer at 22 feet, 20 feet, 18 feet, 16 feet, 


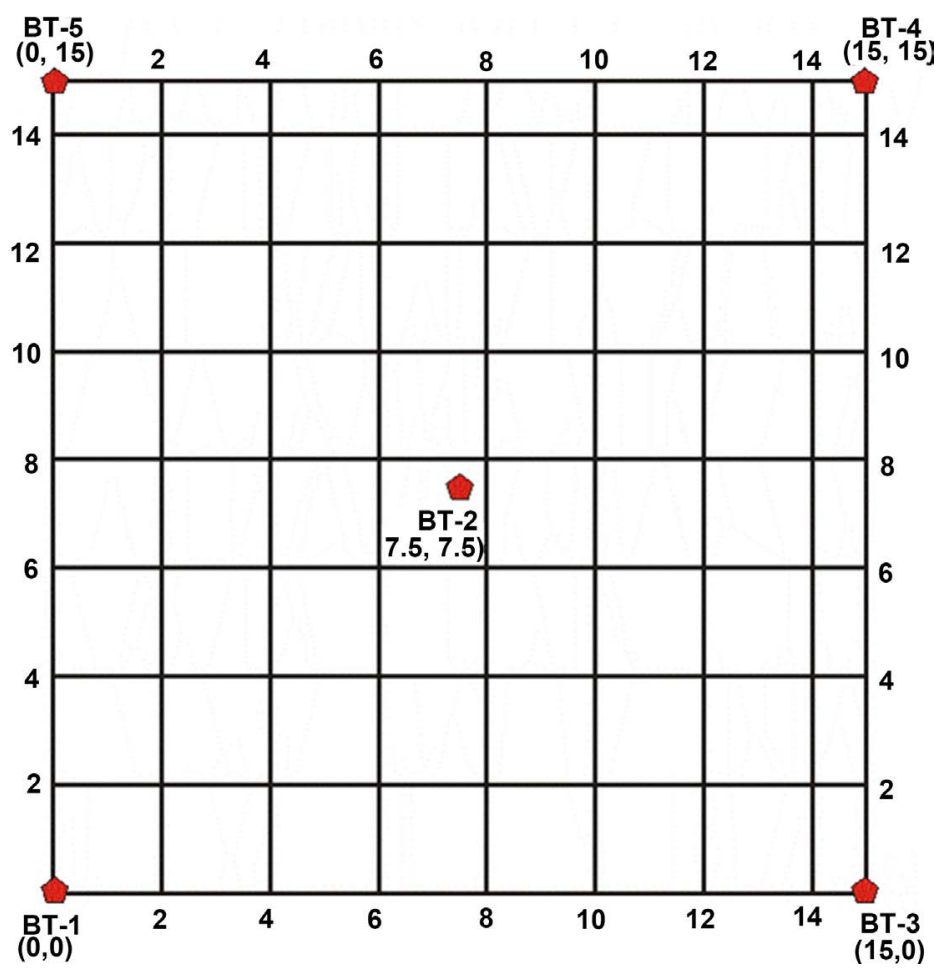

Figure 7. A $15 \times 15$ feet Grid for RSSI Experiment.

and so on, with 1000 readings at each point. The average values of these 1000 readings at each point are shown in Table 1 . The first column is for a distance of 2 feet with last column for 22 feet with each row showing the RSSI measured at that distance.

\section{Results and Discussion}

The results of the measured signals at all five receiver are given in Table 2. For better visual depiction, the surface plots of measured signals at all the five Bluetooth modules are shown in Figure 8. In each surface plot, strong and weak points of the Bluetooth signal strength are shown where the red area depicts the strongest signal strength, the blue area shows the weakest signal strength and the yellow area shows strength between strongest and weakest signals. In ideal cases, the transition from red to yellow to blue should be smooth, with the transmitter closer to the receiver there should be a lot of red and once the transmitter is moved further away, the surface plot should show more blue. But in practice it is not the case due to many reasons such as atmospheric conditions, environmental noise, multipath fading, and ground reflections. These factors affect the actual signal being received at the receiver end, which could make calculations much more complicated.

Here, it would be pertinent to mention that a simple surface plot could not adequately represent the actual phenomenon of the signal interferences and other environmental effects on the RSS. Therefore, 3D Surface plots were generated and analyzed from different angles. It can easily be seen that despite 
Table 1. Mean of calibration data of all five modules of Bluetooth.

\begin{tabular}{cccccccccccc}
\hline & $2 \mathrm{ft}$ & $4 \mathrm{ft}$ & $6 \mathrm{ft}$ & $8 \mathrm{ft}$ & $10 \mathrm{ft}$ & $12 \mathrm{ft}$ & $14 \mathrm{ft}$ & $16 \mathrm{ft}$ & $18 \mathrm{ft}$ & $20 \mathrm{ft}$ & $22 \mathrm{ft}$ \\
\hline BT-1 & -48.0 & -50.0 & -48.4 & -58.1 & -62.7 & -69.4 & -71.3 & -78.8 & -83.3 & -82.1 & -91.3 \\
BT-2 & -45.3 & -47.2 & -53.6 & -61.3 & -65.9 & -67.3 & -70.1 & -75.8 & -82.4 & -86.0 & -90.6 \\
BT-3 & -47.5 & -51.8 & -55.0 & -57.1 & -63.0 & -66.5 & -71.5 & -77.6 & -82.6 & -81.9 & -92.8 \\
BT-4 & -45.8 & -47.7 & -55.4 & -55.6 & -60.2 & -68.3 & -71.9 & -74.2 & -77.9 & -87.7 & -89.0 \\
BT-5 & -44.0 & -49.5 & -54.3 & -57.7 & -65.5 & -69.5 & -71.1 & -77.4 & -78.9 & -86.3 & -87.9 \\
\hline
\end{tabular}

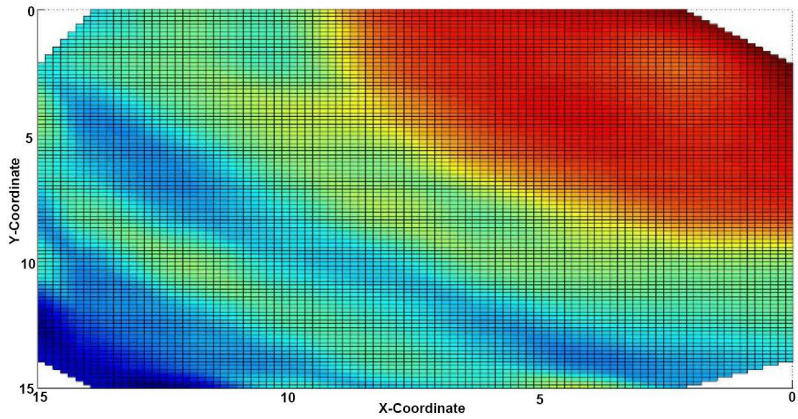

(a)

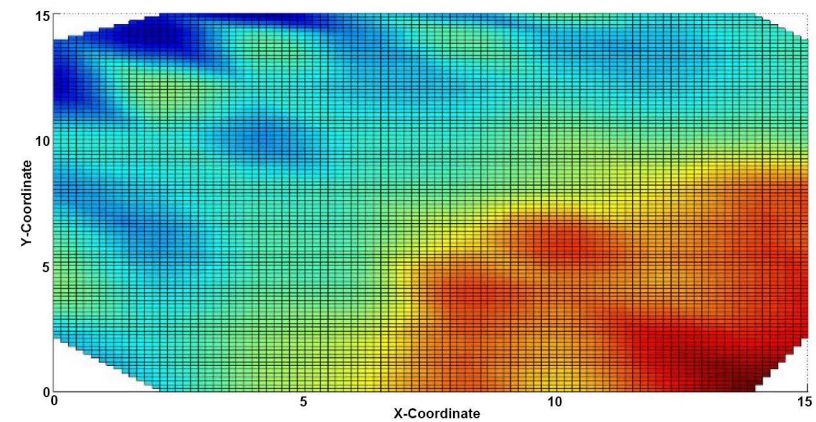

(c)

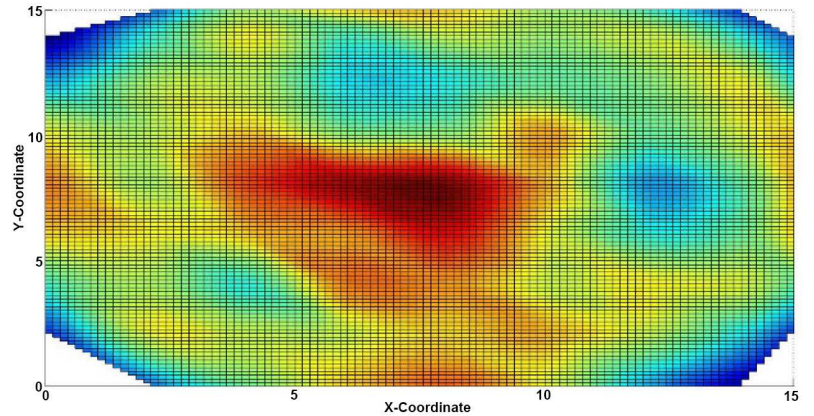

(b)

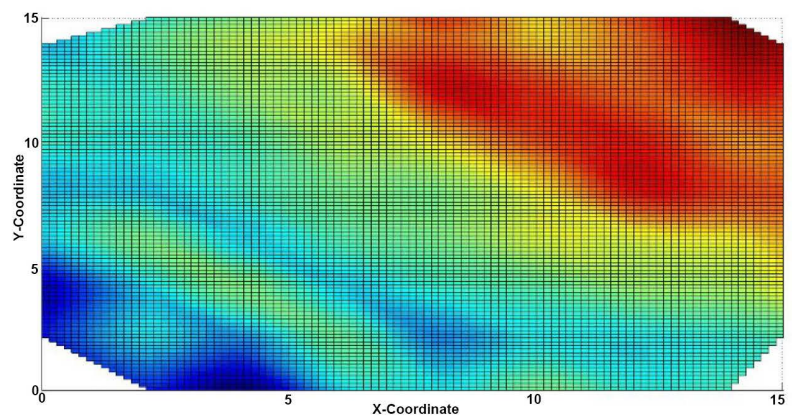

(d)

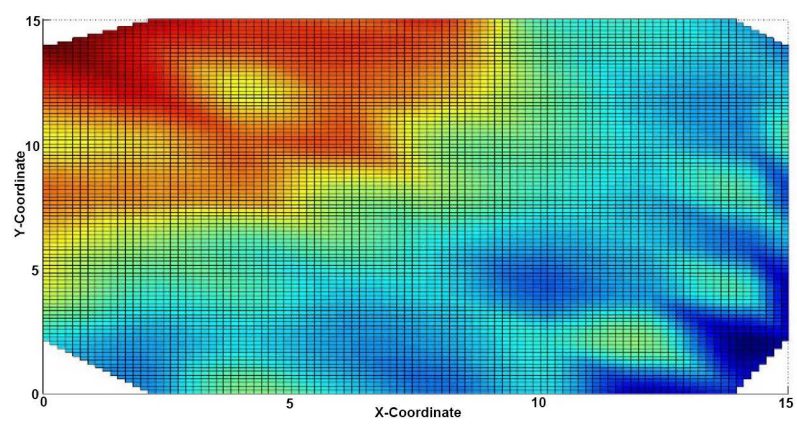

(e)

Figure 8. Surface plot of Bluetooth modules as seen from top at (a) BT-1 (b) BT-2 (c) BT-3 (d) BT-4 (e) BT-5.

certain points being near the receiver, they still have a relatively weak signal strength. This phenomenon dictates that although theoretically, if a transmitter is near the receiver, it should send a strong signal, this is not the case since ideal 
Table 2. Mean of measured data over 15 times $15 \mathrm{ft}$ grid. A set of 25 measurements were made at each grid point.

\begin{tabular}{|c|c|c|c|c|c|c|c|c|c|c|c|}
\hline \multicolumn{2}{|c|}{ Receiver's Coordinates } & \multicolumn{2}{|c|}{ Module 1} & \multicolumn{2}{|c|}{ Module 2} & \multicolumn{2}{|c|}{ Module 3} & \multicolumn{2}{|c|}{ Module 4} & \multicolumn{2}{|c|}{ Module 5} \\
\hline & & Range & RSSI & Range & RSSI & Range & RSSI & Range & RSSI & Range & RSSI \\
\hline 0.0 & 2.0 & 2.0 & -45.2 & 9.3 & -66.3 & 15.1 & -78.3 & 19.8 & -89.5 & 13.0 & -74.8 \\
\hline 0.0 & 4.0 & 4.0 & -49.1 & 8.3 & -63.7 & 15.5 & -63.4 & 18.6 & -89.4 & 11.0 & -61.0 \\
\hline 0.0 & 6.0 & 6.0 & -56.9 & 7.6 & -52.6 & 16.2 & -71.7 & 17.5 & -82.1 & 9.0 & -61.8 \\
\hline 0.0 & 8.0 & 8.0 & -61.2 & 7.5 & -52.2 & 17.0 & -79.6 & 16.6 & -81.2 & 7.0 & -59.7 \\
\hline 0.0 & 10.0 & 10.0 & -67.1 & 7.9 & -56.5 & 18.0 & -72.9 & 15.8 & -71.1 & 5.0 & -60.3 \\
\hline 0.0 & 12.0 & 12.0 & -70.4 & 8.7 & -67.9 & 19.2 & -90.6 & 15.3 & -77.4 & 3.0 & -56.0 \\
\hline 0.0 & 14.0 & 14.0 & -76.7 & 9.9 & -72.0 & 20.5 & -81.1 & 15.0 & -78.3 & 1.0 & -48.4 \\
\hline 2.0 & 0.0 & 2.0 & -53.4 & 9.3 & -69.2 & 13.0 & -73.2 & 19.8 & -86.7 & 15.1 & -80.2 \\
\hline 2.0 & 2.0 & 2.8 & -61.6 & 7.8 & -59.6 & 13.2 & -77.2 & 18.4 & -76.5 & 13.2 & -73.4 \\
\hline 2.0 & 4.0 & 4.5 & -58.9 & 6.5 & -58.5 & 13.6 & -74.1 & 17.0 & -76.4 & 11.2 & -75.2 \\
\hline 2.0 & 6.0 & 6.3 & -55.7 & 5.7 & -56.5 & 14.3 & -75.9 & 15.8 & -72.4 & 9.2 & -68.1 \\
\hline 2.0 & 8.0 & 8.2 & -59.6 & 5.5 & -59.4 & 15.3 & -74.5 & 14.8 & -73.6 & 7.3 & -54.7 \\
\hline 2.0 & 10.0 & 10.2 & -71.7 & 6.0 & -59.9 & 16.4 & -75.7 & 13.9 & -77.8 & 5.4 & -61.9 \\
\hline 2.0 & 12.0 & 12.2 & -76.6 & 7.1 & -54.7 & 17.7 & -69.7 & 13.3 & -72.1 & 3.6 & -55.3 \\
\hline 2.0 & 14.0 & 14.1 & -79.0 & 8.5 & -60.1 & 19.1 & -86.2 & 13.0 & -71.6 & 2.2 & -49.5 \\
\hline 2.0 & 15.0 & 15.1 & -75.7 & 9.3 & -69.4 & 19.8 & -84.4 & 13.0 & -76.8 & 2.0 & -44.9 \\
\hline 4.0 & 0.0 & 4.0 & -55.7 & 8.3 & -56.3 & 11.0 & -71.8 & 18.6 & -91.8 & 15.5 & -70.2 \\
\hline 4.0 & 2.0 & 4.5 & -58.7 & 6.5 & -56.7 & 11.2 & -66.9 & 17.0 & -77.2 & 13.6 & -75.4 \\
\hline 4.0 & 4.0 & 5.7 & -55.8 & 4.9 & -65.3 & 11.7 & -75.8 & 15.6 & -71.5 & 11.7 & -70.6 \\
\hline 4.0 & 6.0 & 7.2 & -53.5 & 3.8 & -53.6 & 12.5 & -73.9 & 14.2 & -74.0 & 9.8 & -72.7 \\
\hline 4.0 & 8.0 & 8.9 & -61.8 & 3.5 & -46.3 & 13.6 & -75.8 & 13.0 & -75.7 & 8.1 & -54.7 \\
\hline 4.0 & 10.0 & 10.8 & -71.0 & 4.3 & -58.2 & 14.9 & -80.7 & 12.1 & -71.7 & 6.4 & -55.8 \\
\hline 4.0 & 12.0 & 12.6 & -73.2 & 5.7 & -54.7 & 16.3 & -75.7 & 11.4 & -68.7 & 5.0 & -58.1 \\
\hline 4.0 & 14.0 & 14.6 & -76.5 & 7.4 & -56.9 & 17.8 & -70.9 & 11.0 & -69.4 & 4.1 & -55.7 \\
\hline 4.0 & 15.0 & 15.5 & -62.4 & 8.3 & -58.1 & 18.6 & -95.0 & 11.0 & -70.9 & 4.0 & -54.1 \\
\hline 6.0 & 0.0 & 6.0 & -55.4 & 7.6 & -51.0 & 9.0 & -64.9 & 17.5 & -78.6 & 16.2 & -72.0 \\
\hline 6.0 & 2.0 & 6.3 & -56.3 & 5.7 & -55.7 & 9.2 & -65.9 & 15.8 & -70.6 & 14.3 & -78.0 \\
\hline 6.0 & 4.0 & 7.2 & -56.8 & 3.8 & -46.6 & 9.8 & -75.1 & 14.2 & -79.1 & 12.5 & -75.2 \\
\hline 6.0 & 6.0 & 8.5 & -57.9 & 2.1 & -49.0 & 10.8 & -67.5 & 12.7 & -73.1 & 10.8 & -67.1 \\
\hline 6.0 & 8.0 & 10.0 & -63.0 & 1.6 & -45.6 & 12.0 & -71.4 & 11.4 & -71.6 & 9.2 & -65.0 \\
\hline 6.0 & 10.0 & 11.7 & -69.4 & 2.9 & -60.7 & 13.5 & -74.9 & 10.3 & -65.3 & 7.8 & -54.7 \\
\hline 6.0 & 12.0 & 13.4 & -78.6 & 4.7 & -59.5 & 15.0 & -80.6 & 9.5 & -70.2 & 6.7 & -55.7 \\
\hline 6.0 & 14.0 & 15.2 & -74.8 & 6.7 & -61.7 & 16.6 & -75.8 & 9.1 & -64.6 & 6.1 & -49.2 \\
\hline 6.0 & 15.0 & 16.2 & -74.9 & 7.6 & -52.6 & 17.5 & -77.2 & 9.0 & -64.2 & 6.0 & -53.3 \\
\hline 8.0 & 0.0 & 8.0 & -54.9 & 7.5 & -56.8 & 7.0 & -58.2 & 16.6 & -80.0 & 17.0 & -77.3 \\
\hline
\end{tabular}




\section{Continued}

\begin{tabular}{|c|c|c|c|c|c|c|c|c|c|c|c|}
\hline 8.0 & 2.0 & 8.2 & -56.3 & 5.5 & -52.7 & 7.3 & -55.5 & 14.8 & -78.4 & 15.3 & -75.3 \\
\hline 8.0 & 4.0 & 8.9 & -63.8 & 3.5 & -48.5 & 8.1 & -53.2 & 13.0 & -75.6 & 13.6 & -73.9 \\
\hline 8.0 & 6.0 & 10.0 & -73.6 & 1.6 & -48.6 & 9.2 & -63.3 & 11.4 & -70.2 & 12.0 & -72.9 \\
\hline 8.0 & 8.0 & 11.3 & -63.4 & 0.7 & 40.5 & 10.6 & -67.4 & 9.9 & -70.3 & 10.6 & -67.7 \\
\hline 8.0 & 10.0 & 12.8 & -75.6 & 2.5 & -58.0 & 12.2 & -77.0 & 8.6 & -59.6 & 9.4 & -68.4 \\
\hline 8.0 & 12.0 & 14.4 & -71.7 & 4.5 & -59.3 & 13.9 & -76.8 & 7.6 & -52.5 & 8.5 & -56.4 \\
\hline 8.0 & 14.0 & 16.1 & -74.9 & 6.5 & -57.9 & 15.7 & -69.1 & 7.1 & -58.7 & 8.1 & -54.7 \\
\hline 8.0 & 15.0 & 17.0 & -79.4 & 7.5 & -49.5 & 16.6 & -80.8 & 7.0 & -54.3 & 8.0 & -53.6 \\
\hline 10.0 & 0.0 & 10.0 & -69.2 & 7.9 & -58.3 & 5.0 & -60.9 & 15.8 & -69.0 & 18.0 & -73.5 \\
\hline 10.0 & 2.0 & 10.2 & -72.7 & 6.0 & -56.4 & 5.4 & -58.7 & 13.9 & -75.7 & 16.4 & -70.0 \\
\hline 10.0 & 4.0 & 10.8 & -64.2 & 4.3 & -54.0 & 6.4 & -54.6 & 12.1 & -74.7 & 14.9 & -81.9 \\
\hline 10.0 & 6.0 & 11.7 & -71.0 & 2.9 & -57.7 & 7.8 & -55.3 & 10.3 & -65.3 & 13.5 & -78.9 \\
\hline 10.0 & 8.0 & 12.8 & -73.4 & 2.5 & -56.3 & 9.4 & -69.1 & 8.6 & -62.4 & 12.2 & -66.6 \\
\hline 10.0 & 10.0 & 14.1 & -76.5 & 3.5 & -54.7 & 11.2 & -71.5 & 7.1 & -57.1 & 11.2 & -68.6 \\
\hline 10.0 & 12.0 & 15.6 & -72.8 & 5.1 & -63.3 & 13.0 & -75.7 & 5.8 & -56.0 & 10.4 & -72.2 \\
\hline 10.0 & 14.0 & 17.2 & -77.0 & 7.0 & -57.1 & 14.9 & -78.0 & 5.1 & -64.6 & 10.1 & -73.0 \\
\hline 10.0 & 15.0 & 18.0 & -75.2 & 7.9 & -55.3 & 15.8 & -70.3 & 5.0 & -59.0 & 10.0 & -71.1 \\
\hline 12.0 & 2.0 & 12.2 & -72.9 & 7.1 & -57.0 & 3.6 & -51.3 & 13.3 & -74.6 & 17.7 & -64.8 \\
\hline 12.0 & 4.0 & 12.6 & -69.9 & 5.7 & -56.2 & 5.0 & -62.0 & 11.4 & -70.6 & 16.3 & -80.4 \\
\hline 12.0 & 6.0 & 13.4 & -76.7 & 4.7 & -63.6 & 6.7 & -59.1 & 9.5 & -67.2 & 15.0 & -73.3 \\
\hline 12.0 & 8.0 & 14.4 & -75.7 & 4.5 & -58.5 & 8.5 & -61.3 & 7.6 & -53.0 & 13.9 & -76.3 \\
\hline 12.0 & 10.0 & 15.6 & -71.2 & 5.1 & -58.3 & 10.4 & -69.2 & 5.8 & -57.6 & 13.0 & -71.1 \\
\hline 12.0 & 12.0 & 17.0 & -84.2 & 6.4 & -55.9 & 12.4 & -76.9 & 4.2 & -57.9 & 12.4 & -74.2 \\
\hline 12.0 & 14.0 & 18.4 & -81.8 & 7.9 & -52.1 & 14.3 & -75.2 & 3.2 & -55.3 & 12.0 & -70.8 \\
\hline 12.0 & 15.0 & 19.2 & -84.2 & 8.7 & -64.7 & 15.3 & -76.8 & 3.0 & -54.5 & 12.0 & -72.1 \\
\hline 14.0 & 2.0 & 14.1 & -74.3 & 8.5 & -61.2 & 2.2 & -51.3 & 13.0 & -74.9 & 19.1 & -86.7 \\
\hline 14.0 & 4.0 & 14.6 & -76.2 & 7.4 & -57.0 & 4.1 & -55.0 & 11.0 & -71.0 & 17.8 & -70.3 \\
\hline 14.0 & 6.0 & 15.2 & -78.4 & 6.7 & -60.1 & 6.1 & -60.2 & 9.1 & -60.0 & 16.6 & -78.9 \\
\hline 14.0 & 8.0 & 16.1 & -74.3 & 6.5 & -61.9 & 8.1 & -55.8 & 7.1 & -54.1 & 15.7 & -73.8 \\
\hline 14.0 & 10.0 & 17.2 & -79.0 & 7.0 & -57.2 & 10.1 & -69.3 & 5.1 & -61.7 & 14.9 & -78.1 \\
\hline 14.0 & 12.0 & 18.4 & -81.0 & 7.9 & -54.8 & 12.0 & -73.6 & 3.2 & -56.4 & 14.3 & -77.9 \\
\hline 14.0 & 14.0 & 19.8 & -87.8 & 9.2 & -65.8 & 14.0 & -75.4 & 1.4 & -47.9 & 14.0 & -73.4 \\
\hline 14.0 & 15.0 & 20.5 & -86.7 & 9.9 & -66.5 & 15.0 & -77.2 & 1.0 & -44.2 & 14.0 & -75.2 \\
\hline 15.0 & 2.0 & 15.1 & -76.6 & 9.3 & -69.6 & 2.0 & -46.3 & 13.0 & -74.2 & 19.8 & -86.0 \\
\hline 15.0 & 4.0 & 15.5 & -67.9 & 8.3 & -59.1 & 4.0 & -49.0 & 11.0 & -61.4 & 18.6 & -83.8 \\
\hline 15.0 & 6.0 & 16.2 & -71.3 & 7.6 & -54.3 & 6.0 & -55.2 & 9.0 & -64.9 & 17.5 & -75.6 \\
\hline 15.0 & 8.0 & 17.0 & -75.2 & 7.5 & -54.2 & 8.0 & -56.7 & 7.0 & -57.9 & 16.6 & -78.4 \\
\hline 15.0 & 10.0 & 18.0 & -74.9 & 7.9 & -55.2 & 10.0 & -67.0 & 5.0 & -56.9 & 15.8 & -70.8 \\
\hline 15.0 & 12.0 & 19.2 & -88.1 & 8.7 & -64.4 & 12.0 & -74.7 & 3.0 & -53.4 & 15.3 & -69.5 \\
\hline 15.0 & 14.0 & 20.5 & -85.3 & 9.9 & -69.6 & 14.0 & -75.5 & 1.0 & -47.5 & 15.0 & -80.3 \\
\hline
\end{tabular}




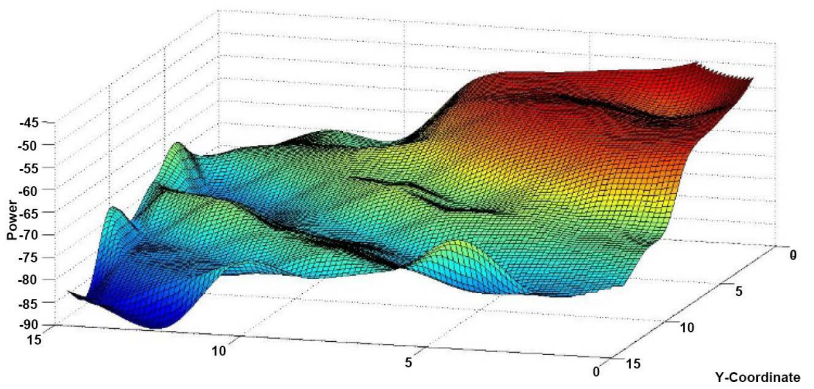

(a)

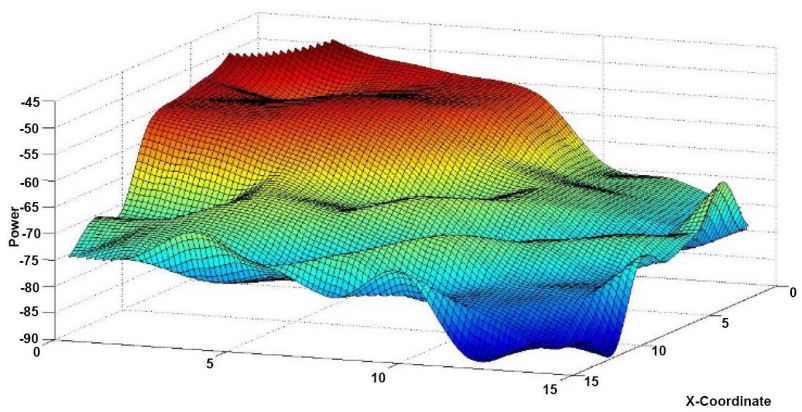

(c)

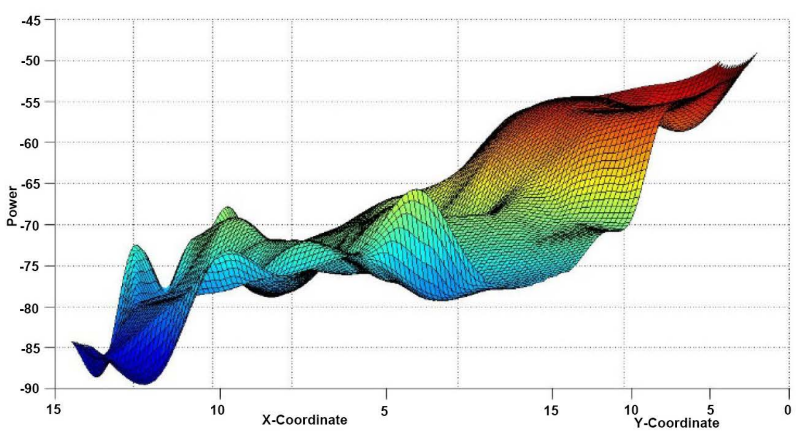

(e)

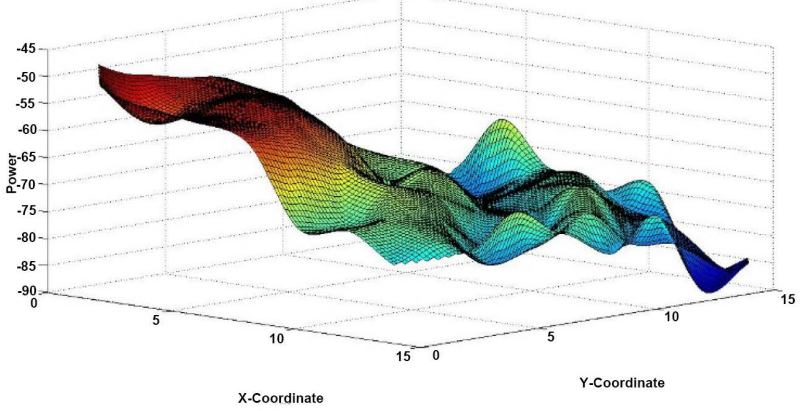

(b)

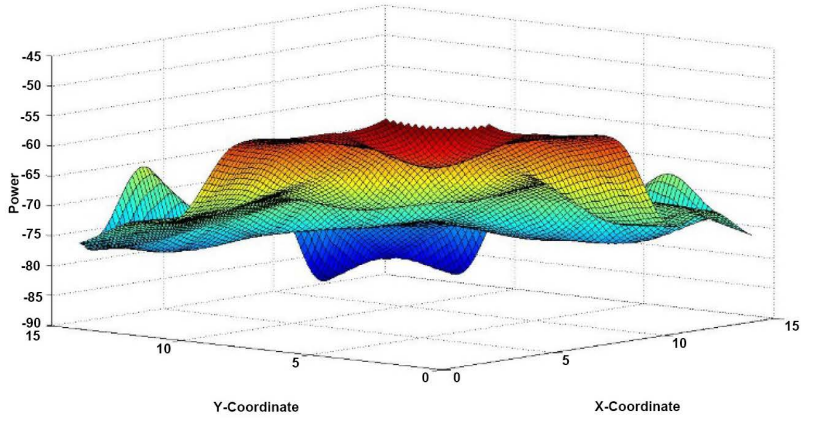

(d)

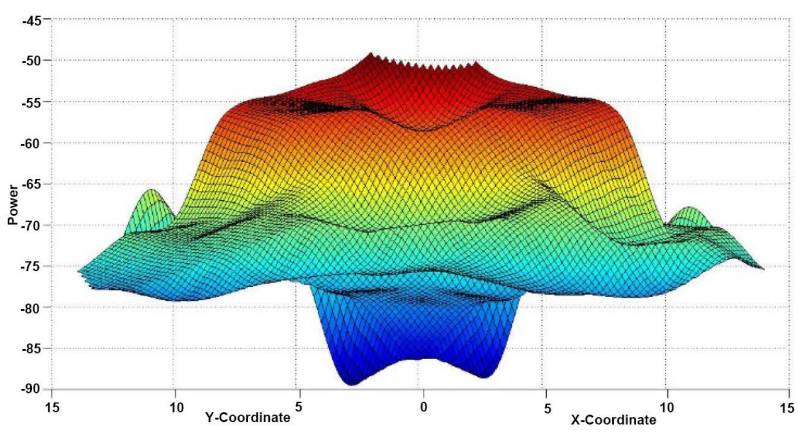

(f)

Figure 9. Surface plot of Bluetooth Module- 1 as seen from (a) $(0,15) \mathrm{ft}$ corner, (b) $(0,0) \mathrm{ft}$ corner, $(\mathrm{c})(15,0) \mathrm{ft}$ corner, $(\mathrm{d})(15,15) \mathrm{ft}$ corner, (e) Right side view, (f) Front side view.

environmental conditions cannot be generated in real life. Thus, to rely completely on the signal strength only, is not possible. The plots generated for Bluetooth module 1 are shown in Figure 9 for reference. The calibration data of Bluetooth Module-1 is shown in Figure 10, in which the dotted line shows the ideal behavior of the power versus distance, whereas the solid line shows actual data captured while calibrating the module.

\section{Conclusions}

Localization for visually impaired people in indoor and outdoor environments, especially in places with unexpected hazards and obstacles, is a current need. Many location-based services, with GPS being used quite popularly in outdoor 


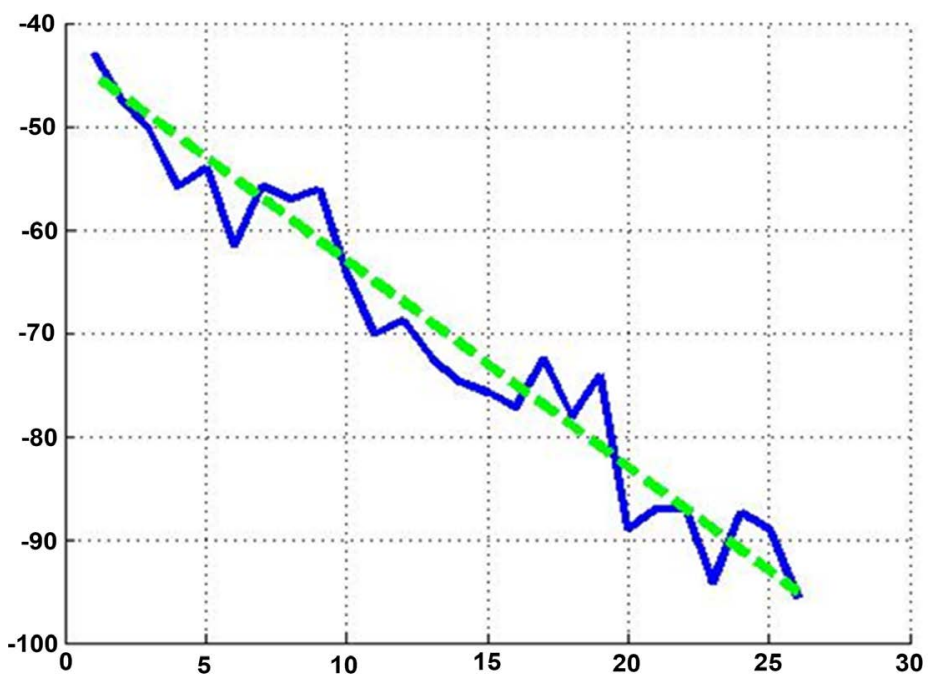

Figure 10. RSSI calibration of Bluetooth module-1.

environments, have been discussed in the literature. For the positioning of devices, TDOA, TOA and RSS have been widely used for the positioning but narrow band signals such as Bluetooth cannot efficiently utilize TDOA or TOA and therefore, RSSI to measure RSS, has been found to be more reliable in which measurement estimations depend heavily on the environmental interference.

The RSSI of Bluetooth systems can further be improved by either improving the existing methodologies to implement them or using fusion techniques employing Kalman filters to combine more than one method to improve the results significantly. This paper proposed a new method of measuring RSSI using trilateration for localization of Bluetooth devices for visually impaired people. To validate the method, class 2 Bluetooth devices were used along with an evaluation board. A software was also developed in National Instruments LabView. The PCB was indigenously designed and manufactured as well.

For the experimental part, five Bluetooth modules were placed on a grid of 15 $\times 15$ feet which acted as receivers whose calibration was already carried out. Surface plots of all the five Bluetooth modules were then generated. In each surface plot, strong and weak points of the Bluetooth were shown. It was also highlighted how many environmental conditions like, atmospheric conditions, environmental noise, multipath fading, reflections, etc., can change the required outputs by affecting the actual signal being received at the receiver end. Last but not least, the results were discussed where in it was shown with the help of surface and 3D plots, how received signal strength varies with external conditions such as atmospheric conditions, environmental noise, multipath fading, reflections, etc.

\section{Conflicts of Interest}

The authors declare no conflicts of interest regarding the publication of this paper. 


\section{References}

[1] Treuillet, S. and Royer, E. (2010) Outdoor/Indoor Vision-Based Localization for Blind Pedestrian Navigation Assistance. International Journal of Image and Graphics, 10, 481-496. https://doi.org/10.1142/S0219467810003937

[2] Hollinger, K. (2016) O\&M for Independent Living: Strategies for Teaching Orientation and Mobility to Older Adults. Journal of Visual Impairment \& Blindness, 110, 33-39. https://doi.org/10.1177/0145482X1611000208

[3] WHO (2007) Visual Impairment and Blindness: Fact Sheet. http://www.who.int/mediacentre/factsheets/fs282/en

[4] Golledge, R.G., Loomis, J.M., Klatzky, R., Flury, A. and Yang, X.-L. (1991) Designing a Personal Guidance System to Aid Navigation without Sight: Progress on the GIS Component. International Journal of Geographical Information Systems, 5, 373-395. https://doi.org/10.1080/02693799108927864

[5] Halder, S. and Ghosal, A. (2014) Mobility-Assisted Localization Techniques in Wireless Sensor Networks: Issues, Challenges and Approaches. In: Koubaa, A. and Khelil, A., Eds., Cooperative Robots and Sensor Networks 2014, Vol. 554, Springer, Berlin, 43-64. https://doi.org/10.1007/978-3-642-55029-4 3

[6] Paum, F., Erhardt, S., Weigel, R. and Koelpin, A. (2017) RSSI-Based Localization with Minimal Infrastructure Using Multivariate Statistic Techniques. IEEE Topical Conference on Wireless Sensors and Sensor Networks, Phoenix, 15-18 January 2017, 69-72.

[7] Kowalik, R. and Kwasniewski, S. (2004) Navigator-A Talking GPS Receiver for the Blind. International Conference on Computers for Handicapped Persons, Paris, 7-9 July 2004, 446-449. https://doi.org/10.1007/978-3-540-27817-7 65

[8] Loomis, J.M., Golledge, R.D. and Klatzky, R.L. (2001) GPS-Based Navigation Systems for the Visually Impaired. Lawrence Erlbaum Associates, Mahwah.

[9] Helal, A., Moore, S.E. and Ramachandran, B. (2001) Drishti: An Integrated Navigation System for Visually Impaired and Disabled. Proceedings 5 th International Symposium on Wearable Computers, Zurich, 8-9 October 2001, 149-156. https://doi.org/10.1109/ISWC.2001.962119

[10] Ran, L., Helal, S. and Moore, S. (2004) Drishti: An Integrated Indoor/Outdoor Blind Navigation System and Service. 2nd IEEE Annual Conference on Pervasive Computing and Communications, Orlando, 14-17 March 2004, 23-30. https://doi.org/10.1109/PERCOM.2004.1276842

[11] Na, J. (2006) The Blind Interactive Guide System Using RFID-Based Indoor Positioning System. In: Miesenberger, K., Klaus, J., Zagler, W.L. and Karshmer, A.I., Eds., Computers Helping People with Special Needs, Springer, Berlin, Heidelberg, 1298-1305. https://doi.org/10.1007/11788713 187

[12] Kulyukin, V., Gharpure, C., Nicholson, J. and Pavithran, S. (2004) RFID in Robot-Assisted Indoor Navigation for the Visually Impaired. IEEE/RSJ International Conference on Intelligent Robots and Systems, Sendai, 28 September-2 October 2004, Vol. 2, 1979-1984.

[13] Hesch, J.A. and Roumeliotis, S.I. (2007) An Indoor Localization Aid for the Visually Impaired. Proceedings 2007 IEEE International Conference on Robotics and Automation, Roma, 10-14 April 2007, 3545-3551. https://doi.org/10.1109/ROBOT.2007.364021

[14] Rueppel, U. and Stuebbe, K.M. (2008) BIM-Based Indoor-Emergency Navigation-System for Complex Buildings. Tsinghua Science and Technology, 13, 362-367. 
https://doi.org/10.1016/S1007-0214(08)70175-5

[15] Jeamwatthanachai, W., Wald, M. and Wills, G. (2017) Map Data Representation for Indoor Navigation by Blind People. International Journal of Chaotic Computing, 4 , 70-78.

[16] Wang, Q., Balasingham, I., Zhang, M. and Huang, X. (2011) Improving RSS-Based Ranging in LOS-NLOS Scenario Using GMMS. IEEE Communications Letters, 15, 1065-1067. https://doi.org/10.1109/LCOMM.2011.080811.111087

[17] Farid, Z., Nordin, R. and Ismail, M. (2013) Recent Advances in Wireless Indoor Localization Techniques and System. Journal of Computer Networks and Communications, 2013, Article ID: 185138. https://doi.org/10.1155/2013/185138

[18] Ahn, H. and Yu, W. (2009) Environmental-Adaptive RSSI-Based Indoor Localization. IEEE Transactions on Automation Science and Engineering, 6, 626-633. https://doi.org/10.1109/TASE.2008.2009126

[19] Kriz, P., Maly, F. and Kozel, T. (2016) Improving Indoor Localization Using Blue-Tooth Low Energy Beacons. Mobile Information Systems, 2016, Article ID: 2083094. https://doi.org/10.1155/2016/2083094

[20] Dabrowski, A., Kardys, P. and Marciniak, T. (2005) Bluetooth Technology Applications Dedicated to Supporting Blind and Hearing as Well as Speech Handicapped People. 47 th International Symposium ELMAR, Zadar, 8-10 June 2005, 295-298. https://doi.org/10.1109/ELMAR.2005.193702

[21] Altini, M., Brunelli, D., Farella, E. and Benini, L. (2010) Bluetooth Indoor Localization with Multiple Neural Networks. IEEE 5 th International Symposium on Wireless Pervasive Computing, Modena, 5-7 May 2010, 295-300. https://doi.org/10.1109/ISWPC.2010.5483748

[22] Millar, S. (1994) Understanding and Representing Space: Theory and Evidence from Studies with Blind and Sighted Children. Oxford Scholarship Online. https://doi.org/10.1093/acprof:oso/9780198521426.001.0001

[23] Park, S. and Hashimoto, S. (2009) Autonomous Mobile Robot Navigation Using Passive RFID in Indoor Environment. IEEE Transactions on Industrial Electronics, 56, 2366-2373. https://doi.org/10.1109/TIE.2009.2013690

[24] Willis, S. and Helal, S. (2004) A Passive RFID Information Grid for Location and Proximity Sensing for the Blind User. 295-300.

[25] Maneesilp, J., Wang, C., Wu, H. and Tzeng, N. (2013) RFID Support for Accurate 3D Localization. IEEE Transactions on Computers, 62, 1447-1459. https://doi.org/10.1109/TC.2012.83

[26] Amemiya, T., Yamashita, J., Hirota, K. and Hirose, M. (2004) Virtual Leading Blocks for the Deaf-Blind: A Real-Time Way-Finder by Verbal-Nonverbal Hybrid Interface and High-Density RFID Tag Space. IEEE Virtual Reality 2004, Chicago, 27-31 March, 2004, 165-287. https://doi.org/10.1109/VR.2004.1310070

[27] D’Atri, E., Medaglia, C.M., Serbanati, A., Ceipidor, U.B., Panizzi, E. and D’Atri, A. (2007) A System to Aid Blind People in the Mobility: A Usability Test and Its Results. Second International Conference on Systems, Sainte-Luce, 22-28 April 2007, 35-35. https://doi.org/10.1109/ICONS.2007.7

[28] Chen, H. and Lin, K. (2011) An Improved Method for Free-Space Antenna-Factor Measurement by Using the Music Algorithm. IEEE Transactions on Electromagnetic Compatibility, 53, 274-282. https://doi.org/10.1109/TEMC.2010.2050775

[29] Agarwal, K. and Chen, X. (2008) Applicability of Music-Type Imaging in Two-Dimensional Electromagnetic Inverse Problems. IEEE Transactions on Antennas and 
Propagation, 56, 3217-3223. https://doi.org/10.1109/TAP.2008.929434

[30] Wong, K.T. and Zoltowski, M.D. (2000) Self-Initiating Music-Based Direction Finding in Underwater Acoustic Particle Velocity-Field Beamspace. IEEE Journal of Oceanic Engineering, 25, 262-273. https://doi.org/10.1109/48.838989

[31] Henault, S., Antar, Y.M.M., Rajan, S., Inkol, R. and Wang, S. (2008) Impact of Mutual Coupling on Wideband Adcock Direction Finders. Canadian Conference on Electrical and Computer Engineering, Niagara Falls, 4-7 May 2008, 001327-001332. https://doi.org/10.1109/CCECE.2008.4564755

[32] Paul, A.S. and Wan, E.A. (2009) RSSI-Based Indoor Localization and Tracking Using Sigma-Point Kalman Smoothers. IEEE Journal of Selected Topics in Signal Processing, 3, 860-873. https://doi.org/10.1109/ISTSP.2009.2032309

[33] Ahn, H. and Ko, K.H. (2009) Simple Pedestrian Localization Algorithms Based on Distributed Wireless Sensor Networks. IEEE Transactions on Industrial Electronics, 56, 4296-4302. https://doi.org/10.1109/TIE.2009.2017097

[34] Ibrahim, M. and Youssef, M. (2012) Cellsense: An Accurate Energy-Efficient GSM Positioning System. IEEE Transactions on Vehicular Technology, 61, 286-296. https://doi.org/10.1109/TVT.2011.2173771

[35] Chen, Z., Zou, H., Jiang, H., Zhu, Q., Soh, Y. and Xie, L. (2015) Fusion of Wifi, Smartphone Sensors and Landmarks Using the Kalman Filter for Indoor Localization. Sensors, 15, 715-732. https://doi.org/10.3390/s150100715

[36] Chen, Z., Zhu, Q. and Soh, Y.C. (2016) Smartphone Inertial Sensor-Based Indoor Localization and Tracking with Ibeacon Corrections. IEEE Transactions on Industrial Informatics, 12, 1540-1549. https://doi.org/10.1109/TII.2016.2579265

[37] Danifis, F. and Cemgil, A. (2017) Model-Based Localization and Tracking Using Bluetooth Low-Energy Beacons. Sensors, 17, pii: E2484.

https://doi.org/10.3390/s17112484

[38] Wu, K., Xiao, J., Yi, Y., Chen, D., Luo, X. and Ni, L.M. (2013) CSI-Based Indoor Localization. IEEE Transactions on Parallel and Distributed Systems, 24, 1300-1309. https://doi.org/10.1109/TPDS.2012.214

[39] Sahu, P.K., Wu, E.H. and Sahoo, J. (2013) Durt: Dual RSSI Trend Based Localization for Wireless Sensor Networks. IEEE Sensors Journal, 13, 3115-3123. https://doi.org/10.1109/ISEN.2013.2257731

[40] Chen, Y., Lymberopoulos, D., Liu, J. and Priyantha, B. (2013) Indoor Localization Using FM Signals. IEEE Transactions on Mobile Computing, 12, 1502-1517. https://doi.org/10.1109/TMC.2013.58

[41] Miller, B.A. and Bisdikian, C. (2000) Understanding and Representing Space: Theory and Evidence from Studies with Blind and Sighted Children. Prentice Hall, Upper Saddle River.

[42] Cheung, K.C., Intille, S.S. and Larson, K. (2006) An Inexpensive Bluetooth-Based Indoor Positioning Hack.

[43] Diaz, J.J.M., Maufies, R.d.A., Soares, R.B., Nakamura, E.F. and Figueiredo, C.M.S. (2010) Bluepass: An Indoor Bluetooth-Based Localization System for Mobile Applications. The IEEE Symposium on Computers and Communications, Riccione, 22-25 June 2010, 778-783. https://doi.org/10.1109/ISCC.2010.5546506

[44] Hossain, A.K.M.M. and Soh, W. (2007) A Comprehensive Study of Bluetooth Signal Parameters for Localization. IEEE 18 th International Symposium on Personal, Indoor and Mobile Radio Communications, Athens, 3-7 September 2007, 1-5. https://doi.org/10.1109/PIMRC.2007.4394215 
[45] Feldmann, S., Kyamakya, K., Zapater, A. and Lue, Z. (2003) An Indoor Bluetooth-Based Positioning System: Concept, Implementation and Experimental Evaluation. International Conference on Wireless Networks, Las Vegas, 23-26 June 2003, 109-113.

[46] Li, D. and Wang, J. (2009) Research of Indoor Local Positioning Based on Bluetooth Technology. 5th International Conference on Wireless Communications, Networking and Mobile Computing, New York, 24-26 September 2009, 1-4. https://doi.org/10.1109/WICOM.2009.5302300

[47] Bohonos, S., Lee, A., Malik, A., Thai, C. and Manduchi, R. (2007) Universal Real-Time Navigational Assistance (URNA): An Urban Bluetooth Beacon for the Blind. In: Proceedings of the 1 st ACM SIGMOBILE International Workshop on Systems and Networking Support for Healthcare and Assisted Living Environments, ACM, New York, 83-88. https://doi.org/10.1145/1248054.1248080

[48] Liu, X., Makino, H., Kobayashi, S. and Maeda, Y. (2007) Design of an Indoor Self-Positioning System for the Visually Impaired-Simulation with RFID and Bluetooth in a Visible Light Communication System. 29th Annual International Conference of the IEEE Engineering in Medicine and Biology Society, Lyon, 22-26 August 2007, 1655-1658. https://doi.org/10.1109/IEMBS.2007.4352625

[49] Pathak, O., Palaskar, P., Palkar, R. and Tawari, M. (2014) Wifi Indoor Positioning System Based on RSSI Measurements from Wifi Access Points-A Tri-Lateration Approach. International Journal of Scientific and Engineering Research, 5, 1234-1238. 